\title{
借鉴德国住房储蓄银行制度完善 中国住房公积金制度的研究综述
}

\section{A Summary of the Research on Perfecting the Housing Provident Fund System in China by Using the German Housing Savings Bank System for Reference 李敏 李静}

Min Li Jing Li

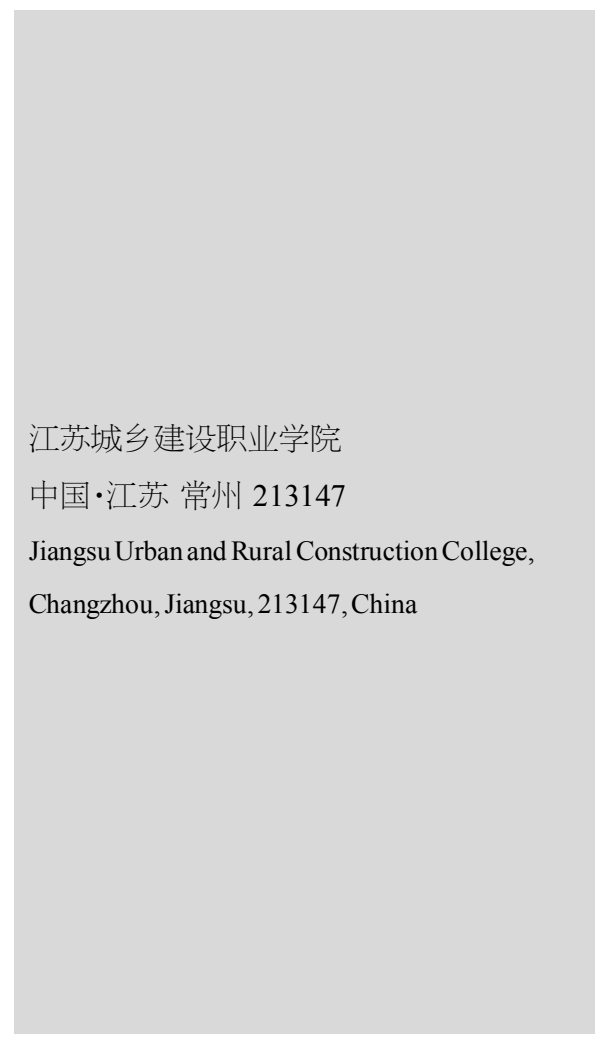

【摘 要】德国住房储蓄银行制度在推动德国住房建设的发展、发挥国家政策性引导作 用、提高国民购房能力等方面发挥了重大作用。而中国住房公积金制度建立近 30 年来, 其 发挥作用的社会经济环境发生了巨大的变化, 问题突显。学习借鉴德国住房储蓄制度完善 中国住房公积金制度是中国学者研究的方向之一。论文从德国住房储蓄银行制度研究、中 国住房公积金制度存在的问题研究和借鉴德国住房储蓄银行制度完善中国住房公积金制 度 3 个方面进行综述,为中国住房公积金制度的进一步改革研究奠定了基础。

【Abstract】The German housing savings bank system has played an important role in promoting the development of housing construction in Germany, giving full play to the role of national policy guidance, and improving the ability of national housing purchase. In the past 30 years since the establishment of the housing provident fund system in China, great changes have taken place in the social and economic environment in which it plays a role, and the problems are prominent. Learning from the German housing savings system to improve the housing provident fund system is one of the research directions of Chinese scholars. This paper summarizes the research on the German housing savings bank system, the existing problems of China's housing provident fund system and the improvement of China's housing provident fund system from the German housing savings bank system, which lays a foundation for the further reform of China's housing provident fund system.

【关键词】住房储蓄;住房公积金;研究; 综述

【Keywords \housing savings; housing provident fund; research; summary

【DOI】10.36012/emr.v1i3.882

\section{1 引言}

中国的住房公积金制度建于 1991 年, 资金来源是职工 单位和个人缴纳的长期住房储金, 实行众人共筹的互助金 融管理模式,贷款资金来源于职工提取后的缴存余额。德 国住房储蓄银行建立于 20 世纪 80 年代，采用合同储蓄的 形式, 是一种互助式的住房金融, 类似于中国的住房公积 金制度。

《2018 年国民经济和社会发展计划》提出“改革住房公积 金制度，研究设立国家住宅政策性金融机构。”德国住房储蓄 银行制度兼具金融机构、互助储蓄和政府政策奖励的多重功 能，对于中国建立国家住宅政策性金融机构具有很好的借鉴
意义。关于借鉴德国住房储蓄银行制度经验的研究, 自中国住 房公积金制度建立后就已开始,近年来的研究更多。论文通过 中国知网(CNKI)中文数据库按主题词检索, 输入 “住房公积 金” 共检索到 12286 条结果, 其中, 期刊 9453 条、博硕士论文 1306 条、其他 1527 条; 输入 “德国住房储蓄银行” 共检索到 139 条结果, 其中, 期刊 77 条、博硕士论文 59 条、其他 3 条, 最早的一篇研究始于 1992 年。论文从“德国住房储蓄银行”检 索结果中研究德国住房储蓄银行制度寻找经验借鉴, 从“德国 住房储蓄银行”和“住房公积金”结合中寻找中国住房公积金 存在的问题及改革方向，考虑到住房公积金制度与经济社会 发展的密切关系, 按时间和相关度进行筛选, 对中国学者 2000 年以后发表的 34 篇文献进行梳理。 


\section{2 德国住房储蓄银行制度研究}

\section{1 德国住房储蓄银行的发展现状}

德国住房储蓄业务是 20 世纪 30 年代政府为解决中西德 合并后国民住房问题时建立的。1 885 年,第一家德国住房储 蓄银行成立,但一直发展较慢。第二次世界大战时期房屋被大 量破坏, 这带来住房金融业的迅猛发展, 直到后来在全德国被 广泛认可一直延续下来 [1]。

住房储蓄银行是由居民自愿参加的民间住宅金融机构， 是按照合同储蓄制度从事金融业务的机构，它的经营完全是 自筹资金, 是具有独资企业法人地位的银行 ${ }^{[2]}$ 。

德国于 1972 年首次颁布了《住房储蓄银行法》, 并于 1991 年进行了修订, 该法对住房储蓄银行的组织框架、业务 范围、合同标准、资金的来源与运用等各方面都做出了界定。 此外，该法还规定了契约储蓄是住房储蓄银行的专有经营范 围 ${ }^{[3]}$, 住房储蓄银行是承办专项住房储蓄业务的专业银行, 其 他全功能商业银行不能承办该业务与住房储蓄银行竞争 ${ }^{[4]}$ 。

德国住房储蓄银行大多不设分支机构, 主要通过先进的 管理系统进行存贷款信息记录跟踪、资金计划调度、配贷指数 计算、还款记录、档案管理等一系列工作, 营销主要依靠与商 业银行建立合作关系，利用其网点资源或通过外围推销员体 系展开。在与住房储蓄银行签订住房储蓄合同的客户中, 有 $80 \%$ 的客户同时申请全功能商业银行抵押贷款，这促进了商 业银行住房贷款业务的发展。到 2008 年,德国每 8 个建房项 目中就有 6 个采用住房储蓄作为融资形式的一部分。由于住 房储蓄的安全性及政府的支持, 住房储蓄业务在德国得到了 空前的发展。目前,德国住房储蓄银行达到了 26 家, 每个州都 有分布, 与德国居民的生活密切相关, 超过 $1 / 3$ 的德国人与住 房储蓄银行签有住房储蓄合同，并选择其作为购房资金的融 资方式之一[5]。

\section{2 德国住房储蓄银行的特点}

\section{2 .1 先存后贷、存贷结合}

德国的住房储蓄制度是一种互助合作形式的住房融资模 式,住房储蓄具有先存后贷、以存定贷的特点同。客户获得贷 款的前提是必须履行存款义务, 贷款行为与存款行为相挂钩, 这是住房储蓄体系区别其他住房金融体系的重要特征 ${ }^{[7]}$ 。德 国住房储蓄银行在借贷资金的发放过程中，除了按常规审查 借款人的支付能力外，还有一套严格的“配贷”机制，对“最低 存款额”作出明确规定, 即凡需获得低息的借款者, 必须按储 贷合同定期交纳储蓄金, 先履行储蓄义务, 并满足最低存款额 要求(只有当储蓄达到所需贷款额的 40\% 50\%,参加储蓄至
少 2 年以上时,才有资格得到所需的贷款 $)^{[8]}$ 。对于放弃贷款 权利的职工, 存款利率与同期无风险的国债利率几乎相等, 也 不收取弃贷合同金额 1\%的管理费。德国针对此类职工设计 的住房储蓄产品为存款利率为 $2.5 \%$, 贷款利率为 $5.3 \%, 2.5 \%$ 的存款利率几乎与同期国债利率相同 ${ }^{[1]}$ 。

\section{2 .2 用途唯一、专款专用}

在德国, 住房储蓄业务只能由专门的机构即住房储蓄银 行来经营。住房储蓄银行是依据政府特定法律设立的,除住房 储蓄融资外不从事其他金融业务 ${ }^{[10]}$ 。当客户最低存款额达到 要求并满足银行规定的其他条件后, 即可得到一笔贷款, 专项 用于购、建住房。住房储蓄银行每月月底对达到最低存款额的 合同计算一次评价值，然后对已符合配贷条件的合同依据评 价值高低进行排序, 按顺序进行配贷, 直到当月的配贷资金用 完为址 ${ }^{[11]}$ 。

\subsection{3 自愿加入、封闭运行}

打算日后购房的人们根据自身的收人状况和购房计划签 订住房储蓄合同, 自愿与储蓄机构一一住房储蓄银行合作进 行专项储蓄,组成一个互助储金集体。对于存入住房储蓄银行 的资金，德国实施了封闭运行，使其独立于德国资本市场之 外, 因此, 资本市场的供求关系、通货膨胀等因素不会影响其 存贷款利率的变动, 这样就避免了利率风险的发生 ${ }^{[12]} 。 2008$ 年 世界金融危机期间，在很多商业银行面临信用危机最终倒闭 的同时, 德国住房储蓄业务得到更多人的认可, 大家觉得这是 一个安全的、不受市场影响的银行, 更多的人选择把钱存入住 房储蓄银行 ${ }^{[13]}$

2.2.4 政府奖励、利率固定

德国的住房储蓄奖励主要有两项：国家住房储蓄奖励和 单位住房储蓄补助, 联邦政府可以根据国家的经济形势和住 房政策调整奖励的力度 ${ }^{[14]}$ 。德国政府明确规定经营住房储蓄 银行免交存款准备金, 同时,在德国有固定居住地和正常纳税 的居民，只要个人应纳税基数收入在 5 万马克之下（夫妻为 10 万马克之下), 就可向政府申请获得住房储蓄奖励。此外, 政府有关法规还规定，对于年应纳税基数收入在 3.5 万马克 以下的个人, 参加住房储蓄后, 可以向雇主申请住房储蓄补助, 雇主补助存入住房储蓄账户的，也可获得国家 $10 \%$ 的奖励。 在储蓄阶段，政府还给予客户所生利息 50\% 100\%的免税补 贴，而且住房储蓄存款者所得到的国家奖励金也是免税的 ${ }^{[15]}$ 。

\section{3 中国住房公积金制度存在的问题研究}

\section{1 强制缴存饱受争议}

中国住房公积金的强制性储蓄忽略了不同员工的消费水 
平, 而且将投资的欲望和个人的消费偏好排斥在外, 严重不利 于公平 ${ }^{[16}$ 。另外, 强制缴存还涉嫌公有权对私有财产权进行干 预 ${ }^{[17]}$ 。中国规定住房公积金强制缴存的法规是 1999 年发布并 于 2002 年修正的《住房公积金管理条例》, 颁布机构是国务 院。作为行政单位, 国务院所颁布的法规不属于法律, 很大程 度上降低了其权威性, 减少了机会主义行为的实施成本 ${ }^{[18]}$ 。

在经济转型和新型城市化的背景下, 大量民营企业、外来 务工人员的涌现使得强制性住房储蓄越来越难以推广普及, 而且过度的强制性储蓄不仅会增加企业的用工成本, 也会成 为刺激消费、扩大内需的障碍 $[19]$ 。

\section{2 缴存覆盖范围窄、分布不均}

由于中国住房公积金政策主要为城镇职工的提供住房保 障, 且强制执行力度不够, 中国住房公积金缴存覆盖范围窄、 分布不均。住房公积金的主要社会资金资源依然局限在一些 行政事业单位、经济效益比较好的垄断性质的行业及国企, 以 及绝大部分股份制性质的企业和外资企业, 至于其他社会人 员, 如大量改制和破产企业的职工、非正规途径就业的群体、 城镇的个体工商户、自由职业人员、城市中的流动人口及进城 务工的农民就没有被纳入住房公积金缴纳序列。其中, 个体劳 动人员、自由职业人员和城市化新人口中的农民工更是住房 公积金的覆盖盲区 ${ }^{[200}$ 。据统计, 截至 2015 年末, 中国住房公积 金实缴单位数量为 231.35 万, 实缴职工人数为 0.1239 亿, 只 占同期参加城镇职工基本养老保险人数的 $35.05 \%$, 占城镇常 住人口总数的 $16.07 \%$ 。

不同地区、不同行业和不同单位在缴存比例和基数上都 有差别, 越是富有的企业越是政策宽松, 导致行业和单位收入 差距被拉大。例如, 国家审计署 2006 年的审计报告指出, 在对 1986 万人的缴存情况进行统计后发现, 其中, $10 \%$ 缴纳较多 公积金的人, 每个月交 1572 元; $10 \%$ 缴纳较少公积金的人只 交 54 元, 两者相差 28 倍 ${ }^{[2]}$ 。

\section{3 存款利率低, 损害了职工的资金收益权}

与新加坡 “高存低贷”不同的是, 中国现有的住房公积金 是“低存低贷”。自 1996 年以来, 中国住房公积金账户计息是 按归集时间区分利率档次, 当年归集和上年结转的分别按活 期存款和三个月定期存款基准利率计息, 2016 年 2 月 21 日 起调整为统一按一年时间定期存款基准利率执行, 调整后的 利率为 $1.5 \%$, 调整前分别为 $0.35 \%$ 和 $1.10 \%$ 。

住房公积金作为一种强制性的住房融资手段, “低存”与 “低贷”配对时, 对住房公积金收益的合理性不存在质疑。但 是, 实际上大部分 “低存” 的人们一辈子也没有享受房公积金 “低贷”的优惠, 他们损失的收益, 被那些贷款超过自己积累额
的群体获得。而损失公积金收益的群体常常是那些最需要住 房保障的低收人人群, 形成了少数低收人群体用现期收入减 少的储蓄补贴高收人群体买房的扭曲的现实, 造成了结果的 不公平 ${ }^{[23]}$ 。有学者认为这种“低存低贷”运行模式, 在缓解缴存 人的购房压力、降低缴存人购房成本的同时, 也存在“劫贫济 富”甚至是“劫贫济贫”的财富转移现象 ${ }^{[24]}$

\section{4 管理体制不健全,资金风险大}

根据中国《住房公积金管理条例》的规定, 住房公积金实 行住房公积金管理委员会决策、住房公积金管理中心运作、银 行专户存储、财政监督的管理原则。作为名义上的公积金管理 决策者, 住房公积金管理委员会实际上是一个虚设机构, 委员 多为政府官员, 致使管委会决策变成了政府部门决策、政府官 员决策 ${ }^{[25]}$ 。公积金管理中心是隶属于政府部门的事业单位, 没 有执法权只有协调权, 由于住房公积金管理委员会在实际工 作中决策流于形式, 管理中心基本代替履行了管委会的全部 职责。

公积金中心作为不以营利为目的的独立的事业单位, 它 不是政府部门,却替政府承担了相当一部分住房保障职能, 负 有强制单位和个人缴存住房公积金的责任。同时, 住房公积金 管理中心需要完成资金归集、放贷等本应由金融机构来执行 的职能, 这就导致住房公积金管理中心定位与实际职能之间 的错位, 进而使中心的职责权利不对等, 不仅降低了住房公积 金管理中心的管理和运行效率, 也给住房公积金的资金安全 增加了风险, 带来了安全隐患 ${ }^{206}$ 。另外, 公积金本身的资金运 作情况也没有公开的披露制度, 这就使得有些地方政府资金 短缺、银行信贷紧张时, 肆意提高存款单位对公积金的贷款申 请要求, 剥夺存款单位对公积金的贷款申请权, 挤占挪用情况 并不鲜见 ${ }^{[2] 。}$

对于财政监管的情况，住房公积金一直以来没有被列入 财政监管的重点, 原因主要是财政部门每年需要监管的单位 数量庞杂, 工作量大, 再加上部分财政部门理解偏差, 认为住 房公积金不是财政资金, 所以没有列入财政监察的重点, 最终 导致无人监管住房公积金的尴过 ${ }^{[28]}$ 。住房公积金管理中心没 有任何自有资产, 经营的绝大部分资产(建房、购房贷款及随 证券投资等)都是来自职工的公积金储蓄,一旦资金运转出现 问题, 中心关门破产, 既不用也无力承担清偿债务的责任, 最 后的苦果只能由全体资产所有者一一职工承受。2005 年 1 月, 中国银行哈尔滨分行河松街支行行长高山与商人李东哲 内外勾结转移该行客户存款 10 多亿元, 事后潜逃加拿大。这 一事件证实中国银行业存在极大的制度漏洞, 而住房公积金 管理面临同样的金融环境。自住房公积金管理系统成立以来, 
市场论坛 Market Forum

银行的存款数额逐年增加, 且因相关规定只存放在固定的几

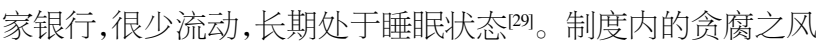
也难以杜绝,2010 年, “全国住房公积金第一案”涉案金额 1.2 亿元被用于奢博。

4 借鉴德国住房储蓄银行制度, 完善中国 住房公积金制度

《2018 年国民经济和社会发展计划》指出“改革住房公积 金制度,研究设立国家住宅政策性金融机构。”这为住房公积 金制度的改革指明了方向。德国住房储蓄制度是一种自愿参 加的封闭式互助融资机制，政府通过政策促进居民积极参与 到住房储蓄以实现住房融资的自助、社会互助和政府资助 ${ }^{[30]}$ 。 和国际上各主要国家相比, 德国较好地解决了住房市场的问 题, 长期保持了住房市场的平稳运行 ${ }^{[3]}$ 。因此, 通过借鉴德国 住房储蓄银行的经验来完善中国的住房公积金制度，探索建 立政策性住房金融机构是目前中国学者研究的主要方向之 一,主要观点如下。

\section{1 加快住房公积金制度立法}

在德国，住房存储政策运行良好依赖于一系列法律体系 的有效保障。德国的住房储蓄银行具有独立法人身份, 而这一 种经营方式的优点在于把现代企业制度融入政策性住房金融 机构, 可以促成激励和约束机制的形成, 经营者必须将自身的 信贷业务规范化,决策行为和投资行为必须谨慎而有效 ${ }^{[32]}$ 。德 国住房储蓄有较为健全和完善的法律制度体系，人们应该科 学地学习和借鉴, 建立健全适合中国国情的住房公积金在缴 存、提取、使用、监督、管理和救济等方面的立法, 并完善中国 的住房保障法律制度体系 ${ }^{[33]}$

\section{2 完善制度设计,设定合理的配贷机制}

为了保证公积金的安全,体现公积金的公正、平等,在进 行公积金贷款时必须建立合理的时间、数额限制条件,以最低 存款额和最低存款年限为例，它并不是简单地以强制方式让 人们多出一点钱, 而是一种个人信用建立和培养的过程。

\section{3 取消强制储蓄,通过政府优惠政策扩大覆盖} 范围

住房储蓄覆盖了经济收人状况不同的社会各类人群, 无 论收人高低均可利用这一住房融资政策来解决购房需求, 社 会覆盖面广。住房储蓄银行的储户自愿选择加入住房储蓄体 系, 通过与储蓄银行签订购房储蓄契约, 按规定履行存款义 务, 达到一定的年限和标准后可以得到银行配贷资格, 获得贷 款权 ${ }^{[34]}$ 。通过取消强制储蓄, 国家对于参与住房储蓄的中低收 入者提供储蓄奖励，这样农民工等体制外中低收入者可以参
与到该制度中来, 享受国家的政策补助; 通过自愿储蓄来获得 信贷, 以解决其在城镇的住房问题。同时, 那些不存在住房问 题的家庭也不需要再缴纳住房公积金, 可以将住房公积金直 接计入工资收人, 省去了通过各种方式提取的麻烦, 也提高了 家庭的可支配收人。

\section{4 向法人性质的金融机构转变}

公积金管理中心要想真正做到高效、安全地运行, 就必须 改变塩尤的行政事业单位的性质和状态, 使之成为独立的为 政府政策目标服务的金融机构, 并向法人性质的金融机构转 变。独立法人地位的确立, 有利于建立法人治理结构, 有利于 规范其会计、审计信息披露、内部风险管理和外部监督机制, 使之更好地发挥融资功能。

\section{5 对中国住房公积金制度的展望}

中国住房公积金制度建立近 30 年来,一直在不断学习新 加坡中央公积金制度的经验,但中国与新加坡环境相差巨大, 新加坡是典型的城市国家, 而中国城市众多、发展不平衡。目 前, 中国住房公积金制度的强制缴存、覆盖范围矣、存款利率 低等诸多问题难以解决, 很多学者对于德国住房储蓄银行制 度的研究也只是基于完善中国住房公积金制度的目的，两种 不同的制度很难融合。根据国家的最新要求, 学者们要转变研 究方向, 把德国住房储蓄银行的经验和中国的国情相结合, 为 国家住宅政策性金融机构的建立提出更多的建议。

\section{参考文献}

[1]孙玥.实现住房公积金制度公平效率目标的路径探索[D].南 京:南京大学,2014

[2]张晓东.互助合作型住房金融资本募集方式的比较与启示 $[\mathrm{J}]$. 内蒙古金融研究,2013(10):85-88.

[3]高勇.政策性住房金融模式的国际比较及对我国的借鉴 [J].吉 林金融研究,2015(7):29-35.

[4]黄河.国外典型住房金融制度[J].中国房地产,2018(17):43-48.

[5]“住宅金融制度改革研究”课题组,刘勇.美、德、日住宅金融机 构发展情况及对我国的启示 [J].开发性金融研究,2018(3):61-68.

[6]李璐.探讨住房融资渠道:德国住房储蓄银行模式在中国 [J].管 理与财富:学术版,2010(3):5.

[7]梁景宗.住房储蓄银行现状与未来发展模式初探[J].华北金融, 2011(10):31-34.

[8]王家庭.建立中国住房储蓄银行的构想[J].理论学刊,2004(4): 36-39.

[9]曹式凤.国外住房保障性制度对优化我国住房公积金制度的 启示[J].商情,2016(33):259-260.

[10]孙凌杉, 德国住房储蓄初探及其对我国公积金制度的启示 [J]. 
现代营销,2013(5):168-169.

[11]张恩照.成立住房储蓄银行, 发展住房储蓄业务[J].中国房地 产金融,2003(2):3-6.

[12]高长海.美国、德国、新加坡住房金融的经验对我国的启示 [J].河南商业高等专科学校学报,2012,25(4):19-21.

[13]张金.住房储蓄与公积金发展问题研究[D].天津:南开大学, 2010.

[14]周龙龙.德国住房金融体系浅析[J].知识经济,2012(7):98.

[15]赵宪武.略论住房公积金与住房储蓄组合的军人住房分配货 币化模式[J].军事经济研究,2009(12):44-47.

[16]李勇辉,修泽睿.我国城镇住房制度改革对收人分配影响分析 [J].商情,2005(5):45-48.

[17]周威,叶剑平.住房公积金制度的法律与经济分析一一写在变 法之前[J].经济体制改革,2009(1):159-163.

[18]裴兵.中国住房公积金制度与德国住房储蓄制度的比较研究: 一个交易费用的视角[J].福建质量管理,2016(15):46.

[19]汪利娜. “还权赋能”完善住房公积金制度[N].经济参考报, 2015-04-16(008).

[20]王辉.改革和完善住房公积金管理问题的研究 [J].科技经济 导刊,2015,27(5):235-236.

[21]曹鹏飞,曹婧.新加坡中央公积金制度及其对完善我国住房公 积金制度的启示 $[\mathrm{J}]$.金融纵横,2017(3):70-76.

[22]张莉.基于公平视角对住房公积金制度的考察 [J].吉林化工 学院学报,2015(9):5-8.
[23]李运华,殷玉如.住房公积金制度设计:公平与效率探讨[J].当 代经济管理,2015(10):50-54.

[24]陈友华.住房公积金制度: 问题、出路与思考 [J].山东社会科 学,2014(3):40-47.

[25]李扬,汪利娜, 殷剑峰.普遍住房保障制度比较和对中国的启 示 [J].财贸经济,2008(1):37-43.

[26]王语奇.我国住房公积金制度存在的问题及对策[J].新视野, 2016(2):99-103.

[27]杨奕.借鉴国外之成功经验完善我国住房公积金制度[J].中 国市场,2015(26):184-186

[28]王海霞.我国住房公积金管理与合理使用问题探讨 [J].现代 经济信息,2011(22):66

[29]腾克斯.住房公积金管理的金融环境探析 [J].中国房地产业, 2011(3):13.

[30]张江涛,闻爽爽. 房价稳定与政策性住房金融体系: 德国的启 示 $[\mathrm{J}]$.金融与经济,2017(6):47-53.

[31]陈洪波,蔡喜洋.全球房地产启示录之稳定的德国[M].北京: 经济管理出版社,2015.

[32]汪利娜. 德国的住房储蓄银行与中国的公积金 [J]. 中外房地 产导报,2000(7):32-35.

[33]李春艳.国外住房公积金制度分析与借鉴 $[\mathrm{J}]$ 合作经济与科 技,2014(15):147-148.

[34]吕媛,宋宁宁.德国住房储蓄体系对我国住房公积金制度的启 示[J].青年时代,2016(24):101. 